\title{
Physicochemical properties and antioxidant activities of hot water extracts of Quercus salicina Blume, Ligustrum japonicum, and Clerodendron trichotomum leaves extracted under different extraction conditions
}

\author{
Seong Jin Hong ${ }^{1}$, Ji-Hyun $\mathrm{Eu}^{2}$, Jong-Bang Eun ${ }^{1 *}$ \\ ${ }^{1}$ Department of Food Science and Technology and BK 21 Plus Program \\ Graduate of Chonnam National University, Gwangju 61186, Korea \\ ${ }^{2}$ Jeollananmdo Forest Resources Research Institute, Naju 58213, Korea
}

\section{추출 조건을 달리한 참가시나무, 광나무, 누리장나무 잎 열수추출물의 이화학적 특성 및 항산화 활성}

\author{
홍성진 ${ }^{1} \cdot$ 어지현 ${ }^{2} \cdot$ 은종방 ${ }^{1 *}$ \\ 1전남대학교 식품공학과/BK21+ 프로그램, ${ }^{2}$ 전라남도 산림자원연구소
}

\begin{abstract}
The physicochemical properties and antioxidant activities of hot water extracts of Quercus salicina Blume (QS), Ligustrum japonicum (LJ), and Clerodendron trichotomum (CT) leaves were investigated. Hot water extracts of QS, $L J$, and CT leaves were prepared at different temperatures $\left(70,80\right.$, and $\left.90^{\circ} \mathrm{C}\right)$ and times $(1,2,3,4$, and $5 \mathrm{~h})$. The lightness $\left(\mathrm{L}^{*}\right)$, redness (a) value, $\mathrm{pH}$ and soluble solid contents of QS extract were lower than those of other extracts. Compared with the LJ and CT extracts, QS extract showed increased total phenolic (533.11 to 692.67 $\mu \mathrm{g} \mathrm{GAE} / \mathrm{g}$ ) and flavonoid (42.13 to $58.40 \mu \mathrm{g} \mathrm{CE} / \mathrm{g})$ contents and higher 1.1-diphenyl-2-picrylhydrazyl (DPPH, 30.21 to $43.02 \%$ ), and 2,2'-azino-bis(3-ethylbenzothiazoline-6-sulphonic acid) (ABTS, 26.08 to $28.28 \%$ ) radical scavenging activities. CT extract showed low total phenolic (212.22 to $361.11 \mu \mathrm{g}$ GAE/g) and flavonoid (8.93 to $22.60 \mu \mathrm{g} \mathrm{CE} / \mathrm{g}$ ) contents, as well as DPPH (5.37 to $11.23 \%$ ), and ABTS (12.17 to $21.47 \%)$ radical scavenging activities at all extraction conditions. For QS, LJ, and CT extracts, the extraction conditions that provided optimal physicochemical properties and antioxidant activities were $80^{\circ} \mathrm{C}$ for $3 \mathrm{~h}, 90^{\circ} \mathrm{C}$ for $4 \mathrm{~h}$, and $90^{\circ} \mathrm{C} 5 \mathrm{~h}$, respectively.
\end{abstract}

Key words : Quercus salicina Blume, Ligustrum japonicum, Clerodendron trichotomum, extraction condition, hot water extract

\section{서 론}

참가시나무(Quercus salicina Blume)는 참나무과에 속하 는 나무로, 일본과 우리나라 남해안 및 제주도에 주로 분포 해 있다. 이 나무는 주로 이뇨, 항염증, 결석 용해 등의 효과

*Corresponding author. E-mail : jbeun@jnu.ac.kr Phone : ※ 개인정보 표시제한 $\mathrm{Fax}: 82-62-530-2149$

Received 28 September 2018; Revised 12 October 2018; Accepted 15 October 2018.

Copyright (c) The Korean Society of Food Preservation. All rights reserved.
가 있다고 하여 민간에서 사용되어 왔으며, 또한 참가시나 무에 대한 연구는 항염증, 항산화, 결석 생성 저해 등의 효과가 있다고 보고 되었다(1). 참가시나무 잎의 주요한 성분은 gallic acid, ellagic acid, tannin, quercetin 등으로 알려 져 있으며, 다양한 유기용매를 이용해 추출한 추출물의 생 리활성능에 대한 연구도 일부 진행되어왔다(2). 하지만 참 가시나무 잎 열수 추출물에 대한 연구보다 열매에 대한 연구가 진행되었으며, 또한 잎을 추출해서 이용하는 소비 자들에게 정확한 정보가 제공되어 있지 않고 있다.

광나무(Ligustrum japonicum)는 우리나라 남해안, 일본 및 대만 등지에서 자생하는 염생식물로서, 이 나무는 주로 
열매를 사용해오고 있다. 열매의 경우 악성종양, 통증완화 등의 치료에 사용했으며 주요한 화합물로는 acetyloleanolic acid, oleanolic acid, ursolic acid, lupeol 등이 있다고 보고되 어 있다(3). 광나무 잎은 민간요법으로 사용되어 왔으며 종기가 났을 때 사용한다고 알려져 있고, 광나무 잎 추출물 에 대한 연구는 메탄올 추출물의 뇌보호 효과와 일부 광나 무 물중탕 추출물의 항산화 활성을 보고된 바 있다 $(4,5)$. 하지만 대부분의 연구는 광나무에 포함된 성분을 규명하는 연구이며, 열수추출물에 대한 연구는 미흡한 실정이다.

누리장나무(Clerodendrum trichotomum)는 혈압을 낮추 는 약재로 알려져 있고 국내에서는 고혈압, 편두통, 이질 등의 민간약재로 사용되었으며, 이 나무는 주로 한국, 일본, 중국 등에 자생하고 있다. 누리장나무는 항산화, 고혈압, 진정효과, 진통효과, 항류머티즘, 항염증 효과가 있다고 보 고되어 있다(6). 일부 연구의 경우 누리장나무의 일부 fl avonoid류인 phenylpropanoid glycosides 등의 새로운 성분 을 검출하였다(7). 국내에서도 누리장나무 잎을 이용한 누 리장나무 차에 대한 연구도 진행되어 있고, 민간요법에서 는 누리장나무 잎을 이용한 차로 음용하고 있지만 추출조건 별로 누리장나무 열수 추출의 이화학적 특성 및 항산화활성 에 대한 연구가 미비한 실정이다.

현재 참가시나무, 광나무, 누리장나무 잎은 민간요법으 로만 사용 중이고, 이들이 어떤 특성을 가지는 지에 대한 연구는 되어 있지 않다. 또한, 이 세 가지 잎들을 열수 추출 하여 일반적으로 음용을 하고 있는 경우가 대부분이다. 그 러나 민간에서 정확한 추출 방법이 정해져 있지 않고, 이 추출물들이 어떤 활성을 가지고 있는지에 대해 잘 알려져 있지 않다. 따라서 본 연구에서는 이 잎들의 추출 조건을 달리하여 추출한 추출물들의 이화학적 특성 및 항산화 활성 을 비교해보고 어떠한 추출 조건에서 뛰어난 특성과 생리 활성을 나타내는가를 조사해보고자 한다.

\section{재료 및 방법}

\section{실험재료 및 추출방법}

참가시나무, 광나무, 누리장나무 잎은 완도에서 재배되 어 2018년 4월에 채취한 것을 농가에서 구입하여 사용하였 다. 참가시나무, 광나무, 누리장나무 잎을 음지에서 3 일간 건조시켜서 사용하였고, 건조된 잎들의 수분함량은 $10 \pm 2 \%$ 로 측정되었는데 수분함량의 경우 $\mathrm{AOAC}(8)$ 를 이용하여 측정하였다. 추출 온도의 경우 $70,80,90^{\circ} \mathrm{C}$ 가 이용되었고, 추출 시간의 경우 $1,2,3,4,5$ 시간으로 설정하여 추출을 진행하였다. 추출 방법의 경우 $500 \mathrm{~mL}$ 삼각플라스크에 각 시료 $4 \mathrm{~g}$ 과 $70,80,90^{\circ} \mathrm{C}$ 온도의 증류수 $400 \mathrm{~mL}$ 를 넣은 후 수직환류냉각기를 부착한 뒤 water bath(JSSB-50T, JSR, Gongju, Korea)를 이용하여 추출하였다. 추출이 끝난 추출
물은 감압여과장치를 이용하여 여과를 진행하였고, 여과지 는 Whatman filter No.1(GE Healthcare UK Ltd., Buckinghamshire, UK)을 이용하였다. 모든 실험은 여과를 마친 참가시나무 잎 열수 추출물(QSLE), 광나무 잎 열수 추출물(LJLE), 누리장나무 잎 열수 추출물(CTLE)을 이용 하여 제조한 뒤 이들의 이화학적 특성과 항산화활성을 측정 하였다.

\section{색 도}

참가시나무, 광나무, 누리장나무 잎 열수 추출물의 색도 는 색차계(CR-400, Minolta, Tokyo, Japan)로 Hunter 색도 값을 측정하였다. 그 결과를 $\mathrm{L}^{*}$ 값(명도) $\mathrm{a}^{*}$ 값(적색도), $\mathrm{b}^{*}$ 값(황색도)으로 나타내었다.

$\mathrm{pH}$

pH는 pH meter(EF-7737, Istek., Seoul, Korea)를 이용하여 참가시나무, 광나무, 누리장나무 잎 열수 추출물 $30 \mathrm{~mL}$ 를 $50 \mathrm{~mL}$ conical tube에 넣고 $\mathrm{pH}$ 를 측정하였다.

\section{가용성 고형분 함량}

각 조건별로 추출한 시료의 가용성 고형분 함량은 추출 물 $10 \mathrm{~mL}$ 를 항량을 구한 알루미늄 수기에 취하여 $105^{\circ} \mathrm{C}$ 에 서 증발 건조시킨 후 무게를 측정하였으며, 추출물 조제에 사용된 원료량(건물량)에 대한 백분율로 나타내었다(9).

\section{총 폴리페놀 함량}

총 폴리페놀 함량은 Folin-Denis법을 변형하여 측정하였 다. 추출물 $1 \mathrm{~mL}$ 를 증류수로 10 배 희석한 추출물 $250 \mu \mathrm{L}$ 를 $1.75 \mathrm{~mL} \mathrm{10 \%} \mathrm{Folin-Ciocalteau} \mathrm{시약} \mathrm{및} 0.5 \mathrm{~mL} 7.5 \% \mathrm{Na}_{2} \mathrm{CO}_{3}$ 용액을 차례로 가하고 혼합한 뒤, 암실에서 30 분 정치한 후 UV-spectrophotometer(Optizen 2120UV, Daejeon, Korea) 를 이용하여 $725 \mathrm{~nm}$ 에서 흡광도를 측정하였다. 표준물질은 gallic acid(Sigma-Aldrich Chemical Co., St. Louis, MO, USA)를 이용하여 제조하였으며, 시료와 동일한 방법으로 분석하여 얻은 표준 검량선을 이용하여 시료 추출물의 총 폴리페놀 함량을 측정하였다(10).

\section{총 플라보노이드 함량}

총 플라보노이드 함량은 Das과 Eun(11)의 분석법을 이용 하여 측정하였다. 먼저 $10 \mathrm{~mL}$ 삼각플라스크에 증류수로 10 배 희석한 추출물 $1 \mathrm{~mL}$ 에 $4 \mathrm{~mL}$ 증류수를 가한 후 혼합하 였다. $5 \% \mathrm{NaNO}_{2} 0.3 \mathrm{~mL}$ 를 가하고 5 분간 정치하였다. 0.3 $\mathrm{mL} 10 \% \mathrm{AlCl}_{3}$ 를 가하고 실온에서 6분간 정치하였다. 정치 가 끝난 혼합물에 $2 \mathrm{~mL} 1 \mathrm{M} \mathrm{NaOH}$ 를 넣은 후 혼합하여 혼합된 용액을 UV-spectrophotometer(Optizen 2120UV) 를 이용하여 $510 \mathrm{~nm}$ 에서 흡광도를 측정하였다. 표준물질은 catechin(Sigma-Aldrich Chemical Co.)을 이용하여 다양한 
농도로 제조한 후 동일한 방법으로 분석하여 얻은 표준 검량선으로부터 시료의 총 플라보노이드 함량을 정량하였 다.

\section{1-Diphenyl-2-picrylhydrazyl(DPPH) radical 소거 활성 측정}

DPPH radical 소거활성 측정의 경우 Lee 등(12)의 방법을 이용하여 측정하였다. $0.12 \mathrm{mM} 190 \mu \mathrm{L} \mathrm{DPPH}$ 용액에 10 $\mu \mathrm{L}$ 추출물을 넣고 30 분간 반응시켰다. 반응시킨 용액을 UV-spectrophotometer(Optizen 2120UV)를 이용하여 517 $\mathrm{nm}$ 에서 흡광도를 측정하였다. $\mathrm{A}_{\mathrm{Cont}}$ 의 경우 추출물이 아닌 증류수를 추출물과 같은 양을 넣고 동일한 방법으로 측정한 흡광도 값을 사용하였다. $\mathrm{A}_{\mathrm{sam}}$ 은 시료 추출물의 흡광도값을 사용하였고, 다음과 같은 계산식을 이용하여 DPPH radical 소거 활성을 측정하였다.

DPPH radical scavenging effect $(\%)=\frac{\mathrm{A}_{\text {cont }}-\mathrm{A}_{\text {sam }}}{\mathrm{A}_{\text {Cont }}} \times 100$

\section{ABTS assay에 의한 radical 소거 활성 측정}

참가시나무, 광나무, 누리장나무 잎 열수추출물의 $\mathrm{ABTS}$ radical 소거 활성을 측정하기 위해, $7.4 \mathrm{mM} \mathrm{ABTS}$ 용액과
$2.6 \mathrm{mM} \mathrm{K}_{2} \mathrm{~S}_{2} \mathrm{O}_{8}$ 을 혼합한 뒤 암소에서 16 시간 동안 반응시 켰다. 반응시킨 혼합물을 $734 \mathrm{~nm}$ 에서 흡광도를 측정하여 흡광도가 $1.1 \pm 0.02$ 범위가 나올 때 까지 메탄올로 희석하였 다. 제조된 $\mathrm{ABTS}$ 용액 $285 \mu \mathrm{L}$ 에 추출물 $25 \mu \mathrm{L}$ 을 96-well plate에 넣고 혼합한 후 2시간 동안 암소에서 반응시켰다. 반응이 끝난 혼합물을 microplate reader를 이용하여 734 $\mathrm{nm}$ 에서 흡광도를 처리하였다. Control의 경우 추출물 대신 증류수를 넣어서 동일한 방법으로 측정하였다. ABTS radical 소거 활성은 다음과 같은 식으로 계산하였다. $\mathrm{A}_{\text {cont }}$ 은 추출물을 넣지 않고 증류수를 넣어서 측정한 것을 이용하였 고, $\mathrm{A}_{\mathrm{sm}}$ 은 시료 추출물을 넣어서 측정한 $\mathrm{ABTS}$ 흡광도 값을 나타낸 것이다(13).

$$
\text { ABTS radical scavenging effect }(\%)=\frac{\mathrm{A}_{\text {Cont }}-\mathrm{A}_{\text {sam }}}{\mathrm{A}_{\text {Cont }}} \times 100
$$

\section{통계처리}

본 실험은 동일 조건의 시료를 세 번 제조하였고 모든 분석은 각 시료별 3회 반복하였다. 측정 결과에 대한 통계적 인 유의성 검정은 SPSS 프로그램(23, IBM Corp., Armonk, $\mathrm{NY}, \mathrm{USA}$ )을 이용하여 분산분석으로 실시하였고, 시료간 의 유의적 차이는 Duncan's multiple range test 방법에 의해 $\mathrm{p}<0.05$ 수준에서 각 처리구별로 유의성을 검증하였다.

Table 1. Color of QSLE, LJLE, and CTLE extracted under different conditions

\begin{tabular}{|c|c|c|c|c|c|c|c|c|c|c|}
\hline \multirow{3}{*}{$\begin{array}{l}\text { Temperature } \\
\left({ }^{\circ} \mathrm{C}\right)\end{array}$} & \multirow{3}{*}{$\begin{array}{l}\text { Extraction } \\
\text { time }(\mathrm{h})\end{array}$} & \multicolumn{9}{|c|}{ Color } \\
\hline & & \multicolumn{3}{|c|}{ QSLE $^{1)}$} & \multicolumn{3}{|c|}{ LJLE $^{2)}$} & \multicolumn{3}{|c|}{ CTLE $^{3)}$} \\
\hline & & $\mathrm{L}^{*}$ & $a^{*}$ & $b^{*}$ & $\mathrm{~L}^{*}$ & $a^{*}$ & $b^{*}$ & $\mathrm{~L}^{*}$ & $a^{*}$ & $b^{*}$ \\
\hline \multirow{5}{*}{70} & 1 & $26.27 \pm 1.92^{\mathrm{NS} 4)}$ & $13.33 \pm 0.69^{\mathrm{NS}}$ & $11.29 \pm 0.69^{\mathrm{f5}}$ & $45.19 \pm 0.14^{\mathrm{bc}}$ & $2.87 \pm 0.03^{\mathrm{d}}$ & $18.99 \pm 0.06^{\text {cde }}$ & $51.56 \pm 0.01^{b}$ & $-1.08 \pm 0.02^{\mathrm{bcd}}$ & $16.23 \pm 0.01^{\mathrm{i}}$ \\
\hline & 2 & $26.16 \pm 0.65$ & $13.35 \pm 1.30$ & $12.45 \pm 0.55^{\mathrm{ef}}$ & $44.67 \pm 0.07^{\mathrm{cd}}$ & $3.05 \pm 0.01^{\mathrm{c}}$ & $19.07 \pm 0.03^{\text {bdde }}$ & $52.18 \pm 0.03^{\mathrm{a}}$ & $-1.43 \pm 0.01^{\mathrm{h}}$ & $16.25 \pm 0.00^{\mathrm{i}}$ \\
\hline & 3 & $26.12 \pm 0.73$ & $13.50 \pm 1.66$ & $12.79 \pm 1.59^{\mathrm{e}}$ & $45.17 \pm 0.77^{\mathrm{bc}}$ & $3.01 \pm 0.07^{\mathrm{c}}$ & $19.28 \pm 0.40^{\mathrm{abc}}$ & $51.53 \pm 0.01^{\mathrm{a}}$ & $-1.09 \pm 0.02^{\mathrm{bcd}}$ & $16.81 \pm 0.01^{\mathrm{h}}$ \\
\hline & 4 & $26.09 \pm 0.55$ & $13.42 \pm 1.33$ & $13.11 \pm 1.24^{\mathrm{cde}}$ & $42.90 \pm 0.10^{\mathrm{hi}}$ & $3.96 \pm 0.03^{b}$ & $19.64 \pm 0.09^{\mathrm{a}}$ & $50.71 \pm 0.0 .56^{\mathrm{cd}}$ & $-1.12 \pm 0.02^{\mathrm{de}}$ & $17.45 \pm 0.23^{\mathrm{f}}$ \\
\hline & 5 & $26.08 \pm 0.43$ & $13.45 \pm 1.10$ & $13.31 \pm 0.44^{\mathrm{cd}}$ & $42.58 \pm 0.09^{\mathrm{i}}$ & $4.16 \pm 0.04^{\mathrm{a}}$ & $19.60 \pm 0.09^{a}$ & $51.57 \pm 0.02^{\mathrm{a}}$ & $-1.40 \pm 0.01^{\mathrm{h}}$ & $17.27 \pm 0.01^{\mathrm{g}}$ \\
\hline \multirow{5}{*}{80} & 1 & $26.36 \pm 1.68$ & $13.32 \pm 2.00$ & $12.35 \pm 1.87^{\mathrm{ef}}$ & $46.10 \pm 0.32^{a}$ & $1.95 \pm 0.02^{\mathrm{i}}$ & $18.83 \pm 0.19^{\mathrm{def}}$ & $50.96 \pm 0.05^{\mathrm{c}}$ & $-1.03 \pm 0.02^{b}$ & $17.43 \pm 0.02^{\mathrm{fg}}$ \\
\hline & 2 & $26.25 \pm 0.26$ & $13.50 \pm 1.17$ & $12.04 \pm 0.26^{\mathrm{ef}}$ & $45.41 \pm 0.04^{\mathrm{b}}$ & $2.17 \pm 0.02^{g h}$ & $19.05 \pm 0.02^{\text {bcde }}$ & $50.93 \pm 0.13^{c}$ & $-1.04 \pm 0.12^{\mathrm{b}}$ & $17.33 \pm 0.08^{\mathrm{fg}}$ \\
\hline & 3 & $26.18 \pm 1.49$ & $13.40 \pm 1.80$ & $13.45 \pm 1.39^{c}$ & $45.30 \pm 0.27^{\mathrm{b}}$ & $2.10 \pm 0.03^{\mathrm{h}}$ & $18.89 \pm 0.19^{\text {cdef }}$ & $50.21 \pm 0.10^{\text {ef }}$ & $-0.91 \pm 0.00^{\mathrm{a}}$ & $18.04 \pm 0.06^{\mathrm{d}}$ \\
\hline & 4 & $26.17 \pm 0.55$ & $13.44 \pm 1.09$ & $13.88 \pm 1.87^{\mathrm{abc}}$ & $44.45 \pm 0.13^{\text {de }}$ & $2.30 \pm 0.03^{\mathrm{ef}}$ & $19.43 \pm 0.04^{\mathrm{ab}}$ & $50.35 \pm 0.10^{\text {de }}$ & $-1.12 \pm 0.02^{\mathrm{de}}$ & $17.99 \pm 0.06^{\mathrm{d}}$ \\
\hline & 5 & $26.15 \pm 0.43$ & $13.45 \pm 1.22$ & $14.12 \pm 0.55^{\mathrm{a}}$ & $44.10 \pm 0.24^{\mathrm{def}}$ & $2.46 \pm 0.06^{\mathrm{f}}$ & $19.26 \pm 0.12^{\mathrm{abcd}}$ & $50.48 \pm 0.01^{\mathrm{de}}$ & $-1.11 \pm 0.01^{\mathrm{cde}}$ & $17.73 \pm 0.00^{e}$ \\
\hline \multirow{5}{*}{90} & 1 & $26.30 \pm 0.37$ & $13.36 \pm 1.14$ & $12.79 \pm 0.31^{\mathrm{e}}$ & $44.51 \pm 0.29^{\mathrm{def}}$ & $2.20 \pm 0.04^{\text {gh }}$ & $19.03 \pm 0.28^{\text {cde }}$ & $50.29 \pm 0.03^{\mathrm{ef}}$ & $-1.20 \pm 0.02^{\mathrm{f}}$ & $18.57 \pm 0.01^{\mathrm{b}}$ \\
\hline & 2 & $26.15 \pm 0.72$ & $13.13 \pm 1.29$ & $12.63 \pm 0.68^{\mathrm{e}}$ & $43.71 \pm 0.57^{\mathrm{g}}$ & $2.11 \pm 0.09^{\mathrm{gh}}$ & $18.59 \pm 0.64^{f}$ & $50.24 \pm 0.02^{\mathrm{ef}}$ & $-1.30 \pm 0.02^{\mathrm{g}}$ & $18.65 \pm 0.01^{b}$ \\
\hline & 3 & $26.12 \pm 0.37$ & $13.23 \pm 1.20$ & $13.39 \pm 0.29^{c}$ & $43.33 \pm 0.12^{\mathrm{gh}}$ & $2.27 \pm 0.02^{\mathrm{fg}}$ & $18.65 \pm 0.08^{\mathrm{ef}}$ & $49.93 \pm 0.02^{\mathrm{f}}$ & $-1.19 \pm 0.00^{f}$ & $18.61 \pm 0.01^{\mathrm{b}}$ \\
\hline & 4 & $26.12 \pm 0.55$ & $13.44 \pm 1.32$ & $13.77 \pm 0.55^{\mathrm{ab}}$ & $43.78 \pm 0.17^{\mathrm{fg}}$ & $2.19 \pm 0.04^{\mathrm{gh}}$ & $18.93 \pm 0.11^{\text {cdef }}$ & $49.40 \pm 0.56^{g}$ & $-1.16 \pm 0.01^{\mathrm{ef}}$ & $18.40 \pm 0.25^{\mathrm{c}}$ \\
\hline & 5 & $26.14 \pm 0.43$ & $13.50 \pm 1.23$ & $13.99 \pm 0.31^{\mathrm{ab}}$ & $43.86 \pm 0.21^{\text {foh }}$ & $2.14 \pm 0.02^{\mathrm{gh}}$ & $18.81 \pm 0.08^{\mathrm{def}}$ & $49.48 \pm 0.01^{g}$ & $-0.92 \pm 0.02^{\mathrm{a}}$ & $18.90 \pm 0.01^{\mathrm{a}}$ \\
\hline
\end{tabular}

${ }^{1)}$ QSLE, Quercus salicina Blume leaf hot water extract.

${ }^{2}$ LLE, Ligustrum japonicum leaf hot water extract.

${ }^{3)}$ CTLE, Clerodendrum trichotomum leaf hot water extract.

${ }^{4}$ NS, no significant.

${ }^{5)-1}$ Means with the same superscripts in a column are not significantly different by Duncan's multiple range test $(p<0.05)$. 


\section{결과 및 고찰}

\section{색 도}

Table 1은 QSLE, LLE, CTLE의 색도를 나타낸 것이다. $\mathrm{QSLE}$ 의 경우 추출시간과 추출온도가 증가하여도 $\mathrm{L}^{*}$ 과 $\mathrm{a}^{*}$ 값은 유의적인 차이를 나타내지 않았다. $\mathrm{b}^{*}$ 값의 경우 추출 시간과 추출온도가 증가할수록 증가하는 경향을 보였다. $\mathrm{LJLE}$ 의 색도는 추출시간과 온도가 증가할수록 $\mathrm{L}^{*}$ 값은 감 소하였고, $\mathrm{b}^{*}$ 값은 증가하였다. CTLE은 추출온도가 증가할 수록 $\mathrm{L}^{*}$ 값이 유의적으로 감소하고 있었으나, 추출 시간의 경우 80 과 $90^{\circ} \mathrm{C}$ 에서 4 시간 이후로는 유의적인 차이를 나타 내지 않았다. $\mathrm{b}^{*}$ 값의 경우 추출 온도와 시간이 증가할수록 유의적으로 증가하였고, $90^{\circ} \mathrm{C}$ 에서 5 시간 추출한 시료에서 가장 높은 값을 나타내었다. Zielinski 등(14)의 연구에 의하 면 추출온도와 시간의 증가는 $\mathrm{a}^{*}$ 와 $\mathrm{L}^{*}$ 값을 유의적으로 감소 시키고 $\mathrm{b}^{*}$ 값 또한 증가시켰다. 이는 페놀, 탄닌, 플라보노이 드, 아미노산 함량의 증가로 인한 것이라고 보고하였다. QSLE, LJLE, CTLE 또한 추출시간과 온도가 증가할수록 $\mathrm{b}^{\star}$ 값이 증가하였고, 기존의 연구와 유사한 경향을 보이고 있었다. 따라서, 본 연구에서의 이들 추출물의 값 증가도 이들 추출물에서의 앞에 언급한 성분들의 함량의 증가로 인해 증가한 것으로 생각된다.

\section{$\mathrm{pH}$}

QSLE, LJLE, CTLE의 $\mathrm{pH}$ 는 Table 2에 나타낸 것과 같다. QSLE의 $\mathrm{pH}$ 는 4.09-4.80의 범위로 나타났으며 추출시간과 온도가 증가할수록 $\mathrm{pH}$ 는 감소하였다. $\mathrm{LJLE}$ 의 $\mathrm{pH}$ 는 5.40-4.73으로 측정되었고, QSLE과 같이 추출 시간과 온도 가 증가할수록 $\mathrm{pH}$ 가 유의적으로 감소하였다. CTLE의 경우 5.17-5.23의 범위로 측정되었고, $90^{\circ} \mathrm{C}$ 에서 측정한 CTLE의 경우 $\mathrm{pH}$ 가 추출시간이 증가할수록 증가하고 있었다. 세 가지 추출물의 경우 $\mathrm{QSLE}$ 의 $\mathrm{pH}$ 가 가장 낮게 측정되었고, $\mathrm{CTLE}$ 이 가장 높은 $\mathrm{pH}$ 로 측정되었다. Seo 등(15)의 연구에 의하면 $\mathrm{pH}$ 가 감소하는 원인으로는 amino carboxyl기에 의 해 산성 물질이 생성되어 $\mathrm{pH}$ 가 감소한다고 하였다. 또한 $\mathrm{pH}$ 는 추출물 제조 시 물의 온도 및 시간, 시료의 양에 영향 을 받는데(16), QSLE, LJLE, CTLE 또한 추출 온도 및 시간 에 영향을 받아 $\mathrm{pH}$ 가 감소하는 것으로 생각된다.

\section{가용성 고형분 함량}

QSLE의 가용성 고형분 함량은 $0.32-0.45 \%$ 의 범위를 나 타내었으며 LJLE의 가용성 고형분 함량은 $0.70-0.83 \%$, $\mathrm{CTLE}$ 의 가용성 고형분은 $0.40-0.52 \%$ 의 함량으로 측정되었 다(Table 3). LLE이 다른 추출물에 비해 높은 가용성 고형 분 함량으로 측정되었고, QSLE이 가장 낮은 가용성 고형분 함량으로 측정되었다. LJLE의 가용성 고형분 함량은 70,8 $0{ }^{\circ} \mathrm{C}$ 의 경우 추출시간이 증가하여도 유의적 차이를 보이지
않았으며 $90^{\circ} \mathrm{C}$ 에서 추출 시 4,5 시간이 가장 높은 함량으로 측정되었다. QSLE는 추출시간과 온도에 영향을 받지 않았 고, CTLE의 경우 모든 추출온도에서 4시간까지는 증가하 였으나 이후에는 유의적 차이를 보이지 않았다. 추출물의 가용성 고형분은 추출 시간에 영향을 받는데, $\mathrm{LJLE}$ 는 $90^{\circ} \mathrm{C}$ 에서 추출 시간이 증가할수록 가용성 고형분 함량이 증가하 였다. Jang 등(17)의 연구에서도 녹차 추출 시간이 가용성 고형분 함량에 영향을 주었고, 대체적으로 추출시간이 증 가할수록 가용성 고형분 함량이 증가한다고 보고하였는데 본 연구에서는 $90^{\circ} \mathrm{C}$ 이상에서 LJLE, CTLE의 경우 추출 시간이 증가할수록 가용성 고형분이 증가하는 결과와 일치 하는 경향을 보이고 있었다.

\section{총 페놀 함량}

식물에서 페놀 화합물은 세포를 보호하고, 자유 라디칼 로부터 유발되는 산화로 인한 손상을 보호해주는 주요한 구성 성분이라고 할 수 있다. Table 4에는 QSLE, LJLE, CTLE의 총 페놀 함량을 나타내었다. QSLE, LLE, CTLE의 총 페놀 함량의 경우 QSLE의 총 페놀 함량이 다른 두 추출 물에 비해 높았다. QSLE와 LJLE의 경우 각각 553.11-

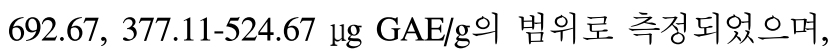

Table 2. $\mathrm{pH}$ of QSLE, LJLE, and CTLE extracted under different conditions

\begin{tabular}{|c|c|c|c|c|}
\hline \multirow{2}{*}{$\begin{array}{c}\text { Temperature } \\
\left({ }^{\circ} \mathrm{C}\right)\end{array}$} & \multirow{2}{*}{$\begin{array}{l}\text { Extraction } \\
\text { time (h) }\end{array}$} & \multicolumn{3}{|c|}{$\mathrm{pH}$} \\
\hline & & QSLE $^{1)}$ & LLLE $^{2)}$ & CTLE $^{3)}$ \\
\hline \multirow{5}{*}{70} & 1 & $4.80 \pm 0.02^{\mathrm{a} 4)(5)}$ & $5.23 \pm 0.01^{\mathrm{cB}}$ & $5.32 \pm 0.03^{\mathrm{deA}}$ \\
\hline & 2 & $4.76 \pm 0.01^{\mathrm{cC}}$ & $5.19 \pm 0.01^{\mathrm{dB}}$ & $5.34 \pm 0.01^{\mathrm{dA}}$ \\
\hline & 3 & $4.68 \pm 0.01^{\mathrm{fC}}$ & $5.21 \pm 0.01^{\mathrm{dB}}$ & $5.26 \pm 0.01^{\mathrm{fA}}$ \\
\hline & 4 & $4.67 \pm 0.01^{\mathrm{fC}}$ & $4.91 \pm 0.01^{\mathrm{fB}}$ & $5.22 \pm 0.01^{\mathrm{gA}}$ \\
\hline & 5 & $4.65 \pm 0.01^{\mathrm{g} C}$ & $4.90 \pm 0.01^{\mathrm{EB}}$ & $5.17 \pm 0.01^{\mathrm{iA}}$ \\
\hline \multirow{5}{*}{80} & 1 & $4.78 \pm 0.01^{\mathrm{bC}}$ & $5.27 \pm 0.02^{\mathrm{bB}}$ & $5.42 \pm .0 .01^{\mathrm{bA}}$ \\
\hline & 2 & $4.72 \pm 0.01^{\mathrm{eC}}$ & $5.40 \pm 0.01^{\mathrm{aA}}$ & $5.33 \pm 0.01^{\mathrm{deB}}$ \\
\hline & 3 & $4.75 \pm 0.01^{\mathrm{dC}}$ & $5.26 \pm 0.02^{\mathrm{bB}}$ & $5.38 \pm 0.01^{\mathrm{cA}}$ \\
\hline & 4 & $4.74 \pm 0.01^{\mathrm{dC}}$ & $4.82 \pm 0.01^{\mathrm{hB}}$ & $5.23 \pm 0.01^{\mathrm{gA}}$ \\
\hline & 5 & $4.74 \pm 0.01^{\mathrm{dC}}$ & $4.83 \pm 0.01^{\mathrm{ghB}}$ & $5.23 \pm 0.01^{\mathrm{gA}}$ \\
\hline \multirow{5}{*}{90} & 1 & $4.23 \pm 0.01^{\mathrm{hC}}$ & $5.12 \pm 0.02^{\mathrm{eB}}$ & $5.32 \pm 0.01^{\mathrm{eA}}$ \\
\hline & 2 & $4.16 \pm 0.01^{\mathrm{iC}}$ & $4.85 \pm 0.00^{\mathrm{gB}}$ & $5.20 \pm 0.01^{\mathrm{hA}}$ \\
\hline & 3 & $4.10 \pm 0.0 \mathrm{1}^{\mathrm{jc}}$ & $4.80 \pm 0.01^{\mathrm{iB}}$ & $5.37 \pm 0.01^{\mathrm{cA}}$ \\
\hline & 4 & $4.10 \pm 0.01^{\mathrm{jC}}$ & $4.77 \pm 0.02^{\mathrm{B}}$ & $5.52 \pm 0.01^{\mathrm{aA}}$ \\
\hline & 5 & $4.09 \pm 0.01^{\mathrm{jC}}$ & $4.73 \pm 0.01^{\mathrm{kB}}$ & $5.50 \pm 0.01^{\mathrm{aA}}$ \\
\hline
\end{tabular}

${ }^{1)}$ QSLE, Quercus salicina Blume leaf hot water extract.

${ }^{2}$ LJLE, Ligustrum japonicum leaf hot water extract.

${ }^{3)}$ CTLE, Clerodendrum trichotomum leaf hot water extract.

${ }^{4) a-k}$ Means with the same superscripts in a column are not significantly different by Duncan's multiple range test $(\mathrm{p}<0.05)$

${ }^{5 A-C}$ Means with the same superscipts in a row are not significantly different by Duncan's multiple range test $(\mathrm{p}<0.05)$. 
Table 3. Soluble solid contents of QSLE, LJLE, and CTLE extracted under different conditions

\begin{tabular}{|c|c|c|c|c|}
\hline \multirow{2}{*}{$\begin{array}{c}\text { Temperature } \\
\left({ }^{\circ} \mathrm{C}\right)\end{array}$} & \multirow{2}{*}{$\begin{array}{l}\text { Extraction } \\
\text { time (h) }\end{array}$} & \multicolumn{3}{|c|}{ Soluble solid content $(\%)$} \\
\hline & & QSLE $^{1)}$ & LJLE $^{2)}$ & CTLE $^{3)}$ \\
\hline \multirow{5}{*}{70} & 1 & $0.32 \pm 0.00^{64)(5)}$ & $0.70 \pm 0.01^{\mathrm{bA}}$ & $0.43 \pm 0.01^{\mathrm{eAB}}$ \\
\hline & 2 & $0.37 \pm 0.00^{\mathrm{abC}}$ & $0.70 \pm 0.00^{\mathrm{bA}}$ & $0.44 \pm 0.01^{\mathrm{det} B}$ \\
\hline & 3 & $0.39 \pm 0.01^{\mathrm{abC}}$ & $0.72 \pm 0.03^{\mathrm{bA}}$ & $0.44 \pm 0.01^{\operatorname{det} B}$ \\
\hline & 4 & $0.37 \pm 0.01^{\mathrm{abC}}$ & $0.72 \pm 0.01^{\mathrm{bA}}$ & $0.52 \pm 0.01^{\mathrm{aB}^{\mathrm{B}}}$ \\
\hline & 5 & $0.38 \pm 0.00^{\mathrm{abC}}$ & $0.72 \pm 0.01^{\mathrm{bA}}$ & $0.52 \pm 0.05^{\mathrm{aB}}$ \\
\hline \multirow{5}{*}{80} & 1 & $0.36 \pm 0.01^{\mathrm{abC}}$ & $0.70 \pm 0.00^{\mathrm{bA}}$ & $0.44 \pm 0.04^{\operatorname{detB}}$ \\
\hline & 2 & $0.41 \pm 0.00^{\mathrm{abC}}$ & $0.73 \pm 0.01^{\mathrm{bA}}$ & $0.45 \pm 0.04^{\text {bcdeA }}$ \\
\hline & 3 & $0.42 \pm 0.02^{\mathrm{aC}}$ & $0.72 \pm 0.01^{\mathrm{bA}}$ & $0.45 \pm 0.01^{\text {cdetB }}$ \\
\hline & 4 & $0.41 \pm 0.01^{\mathrm{abC}}$ & $0.72 \pm 0.01^{\mathrm{bA}}$ & $0.49 \pm 0.01^{\mathrm{abcdB}}$ \\
\hline & 5 & $0.42 \pm 0.02^{\mathrm{aC}}$ & $0.72 \pm 0.01^{\mathrm{bA}}$ & $0.50 \pm 0.02^{\mathrm{abB}}$ \\
\hline \multirow{5}{*}{90} & 1 & $0.43 \pm 0.00^{a \mathrm{~B}}$ & $0.72 \pm 0.01^{\mathrm{bA}}$ & $0.40 \pm 0.03^{\mathrm{eB}}$ \\
\hline & 2 & $0.42 \pm 0.01^{\mathrm{aB}}$ & $0.72 \pm 0.01^{\mathrm{bA}}$ & $0.43 \pm 0.05^{\mathrm{e} B \mathrm{~B}}$ \\
\hline & 3 & $0.45 \pm 0.01^{\mathrm{aB}}$ & $0.72 \pm 0.01^{\mathrm{bA}}$ & $0.47 \pm 0.02^{\text {bcdeB }}$ \\
\hline & 4 & $0.42 \pm 0.01^{\mathrm{aC}}$ & $0.80 \pm 0.14^{\mathrm{aA}}$ & $0.47 \pm 0.02^{\text {abcceB }}$ \\
\hline & 5 & $0.45 \pm 0.19^{\mathrm{aB}}$ & $0.83 \pm 0.08^{\mathrm{aA}}$ & $0.50 \pm 0.03^{\mathrm{abcB}}$ \\
\hline
\end{tabular}

${ }^{1)}$ QSLE, Quercus salicina Blume leaf hot water extract.

${ }^{2)}$ LULE, Ligustrum japonicum leaf hot water extract.

${ }^{3)}$ CTLE, Clerodendrum trichotomum leaf hot water extract.

${ }^{4) a-f}$ Means with the same superscripts in a column are not significantly different by Duncan's multiple range test $(\mathrm{p}<0.05)$.

${ }_{5 A-C}$ Means with the same superscripts in a row are not significantly different by Duncan's multiple range test $(\mathrm{p}<0.05)$.

$70^{\circ} \mathrm{C}$ 에서는 추출 시간이 증가함에 따라 증가하였으나, 80 과 $90^{\circ} \mathrm{C}$ 에서는 3 시간 이후에는 추출 시간이 증가하여도 유의적인 차이가 없었다. CTLE의 경우 212.22-316.11 $\mathrm{\mu g}$ $\mathrm{GAE} / \mathrm{g}$ 의 범위로 측정되었고 추출온도와 시간이 증가할수 록 총 페놀 함량이 증가하였으나, QSLE와 LJLE에 비해 낮은 총 페놀 함량으로 측정되었다. 또한 라벤더, 후추, 감초 열수 추출물의 경우 각각 $153.92 \mu \mathrm{g}, 54.3 \mu \mathrm{g}, 185.7$ $\mu \mathrm{g}$ 으로 측정되었는데, QSLE, LJLE, CTLE와 비교하였을 때 세 가지 추출물이 보고된 열수 추출물에 비해 높은 총 페놀 함량으로 측정되었다(18-20). Kim 등(21)의 연구에서 는 콩나물에서 추출 온도가 높고 시간이 증가할수록 더 많은 폴리페놀이 검출된다고 보고하였는데, 본 실험에서의 추출한 세 가지 추출물 모두 추출 온도와 시간이 증가할수 록 총 페놀함량이 증가한다는 결과와 일치하는 경향을 보였 다.

\section{플라보노이드 함량}

QSLE, LJLE, CTLE의 총 플라보노이드 함량은 Table 5와 같다. QSLE의 경우 50.59-58.40 $\mathrm{\mu g} \mathrm{CE/g}$ 의 범위를 나타내고 있으며, 모든 추출 온도에서 3시간 이후에는 추출 시간이 증가하여도 유의적인 차이가 없었다. LLEE의 총 플라보노
Table 4. Total phenolic contents of QSLE, LJLE, and CTLE extracted under different conditions

\begin{tabular}{|c|c|c|c|c|}
\hline \multirow{2}{*}{$\begin{array}{c}\text { Temperature } \\
\left({ }^{\circ} \mathrm{C}\right)\end{array}$} & \multirow{2}{*}{$\begin{array}{l}\text { Extraction } \\
\text { time (h) }\end{array}$} & \multicolumn{3}{|c|}{ Total phenolic content ( $\mu \mathrm{g}$ GAE/g) } \\
\hline & & QSLE $^{1)}$ & $\operatorname{LJLE}^{2)}$ & CTLE $^{3)}$ \\
\hline \multirow{5}{*}{70} & 1 & $553.11 \pm 58.51^{\mathrm{dfg}(\mathrm{g}) \mathrm{A} 5)}$ & $377.11 \pm 0.77^{\mathrm{hB}}$ & $212.22 \pm 0.77^{\mathrm{iC}}$ \\
\hline & 2 & $623.56 \pm 23.01^{\mathrm{cdA}}$ & $385.56 \pm 0.77^{\mathrm{hB}}$ & $218.89 \pm 0.77^{\mathrm{iC}}$ \\
\hline & 3 & $649.78 \pm 12.99^{\mathrm{bcA}}$ & $415.78 \pm 0.77^{\mathrm{gB}}$ & $252.22 \pm 0.77^{\mathrm{gC}}$ \\
\hline & 4 & $577.33 \pm 31.27^{\mathrm{dfA}}$ & $482.00 \pm 2.31^{\mathrm{AB}}$ & $258.00 \pm 1.33^{\mathrm{fC}}$ \\
\hline & 5 & $588.44 \pm 10.10^{\mathrm{deA}}$ & $452.22 \pm 0.77^{\mathrm{B}}$ & $252.22 \pm 0.77^{\mathrm{hC}}$ \\
\hline \multirow{5}{*}{80} & 1 & $544.67 \pm 39.41^{\text {fghA }}$ & $424.22 \pm 28.73^{\mathrm{fgB}}$ & $238.89 \pm 0.77^{\mathrm{hC}}$ \\
\hline & 2 & $640.44 \pm 28.50^{\mathrm{cA}}$ & $439.33 \pm 12.22^{\mathrm{efB}}$ & $228.22 \pm 0.77^{\mathrm{hC}}$ \\
\hline & 3 & $662.22 \pm 21.79^{\mathrm{abcA}}$ & $530.89 \pm 0.77^{\mathrm{CB}}$ & $258.00 \pm 1.33^{\mathrm{eC}}$ \\
\hline & 4 & $692.67 \pm 37.87^{\mathrm{aA}}$ & $514.00 \pm 13.92^{\mathrm{abBc}}$ & $255.33 \pm 2.55^{\mathrm{fC}}$ \\
\hline & 5 & $686.89 \pm 29.62^{\mathrm{abA}}$ & $504.33 \pm 14.69^{\text {bcdB }}$ & $270.00 \pm 12.25^{\mathrm{eC}}$ \\
\hline \multirow{5}{*}{90} & 1 & $649.44 \pm 58.90^{b c d A}$ & $502.44 \pm 16.99^{\text {bcdB }}$ & $318.89 \pm 0.77^{\mathrm{dC}}$ \\
\hline & 2 & $681.33 \pm 31.15^{\mathrm{bcA}}$ & $492.22 \pm 13.92^{\mathrm{cdB}}$ & $328.22 \pm 7.34^{\mathrm{cC}}$ \\
\hline & 3 & $681.27 \pm 40.22^{\mathrm{abcA}}$ & $512.67 \pm 26.48^{\mathrm{abcB}}$ & $349.11 \pm 0.77^{\mathrm{bC}}$ \\
\hline & 4 & $680.12 \pm 29.62^{\mathrm{abcA}}$ & $524.67 \pm 1.54^{\mathrm{abB}}$ & $358.89 \pm 2.78^{\mathrm{aC}}$ \\
\hline & 5 & $681.44 \pm 21.79^{\mathrm{abcv}}$ & $523.33 \pm 3.53^{\mathrm{abB}}$ & $361.11 \pm 0.77^{\mathrm{aC}}$ \\
\hline
\end{tabular}

${ }^{1)}$ QSLE, Quercus salicina Blume leaf hot water extract.

${ }^{2}$ LJLE, Ligustrum japonicum leaf hot water extract.

${ }^{3}$ CTLE, Clerodendrum trichotomum leaf hot water extract.

${ }^{4) a-i}$ Means with the same superscripts in a column are not significantly different by Duncan's multiple range test $(\mathrm{p}<0.05)$.

${ }_{5 \mathrm{~A}-\mathrm{C}}$ Means with the same superscipts in a row are not significantly different by Duncan's multiple range test $(\mathrm{p}<0.05)$.

이드 함량은 $70^{\circ} \mathrm{C}$ 의 경우 4 시간 이후, $80^{\circ} \mathrm{C}$ 에서는 3 시간 이후에 유의적인 차이를 나타내지 않았고, $90^{\circ} \mathrm{C}$ 에서는 추 출시간이 증가할수록 총 플라보노이드 함량이 증가하였다. $\mathrm{CTLE}$ 은 8.93-22.60 $\mathrm{\mu g} \mathrm{CE} / \mathrm{g}$ 의 범위를 나타냈으며, $90^{\circ} \mathrm{C}$ 에 서 가장 높은 총 플라보노이드 함량으로 측정되었고 3 시간 이후로는 유의적 차이가 없었다. 세 가지 추출물 중 QSLE 에서 가장 높은 총 플라보노이드 함량이 측정되었으며, LJLE, CTLE 순으로 플라보노이드 함량이 높았다. 추출시 간과 온도가 증가할수록 총 플라보노이드 함량이 증가한 이유는 잎 내부의 세포벽 내에 존재하는 플라보노이드가 추출온도와 시간이 증가하면서 용매에 의해 잎 내부에 있는 성분들이 수용성이 증가하여 더 많이 추출되어 나오게 되므 로 증가하는 것으로 생각되었다. Zhou 등(22)의 연구에 따 르면 추출시간은 총 플라보노이드 수율에 영향을 미치는 데, 추출시간이 길어질수록 총 플라보노이드 함량을 향상 시키고, 이러한 영향은 세포막에서 용매로의 용해 및 확산 에 필요한 시간이 원인이기 때문이라고 하였다. 이러한 이 유로 QSLE, LJLE, CTLE의 총 플라보노이드 함량이 추출 시간과 온도에 따라 증가하는 것으로 생각되었다. 
Table 5. Total flavonoid contents of QSLE, LJLE, and CTLE extracted under different conditions

\begin{tabular}{|c|c|c|c|c|}
\hline \multirow{2}{*}{$\begin{array}{l}\text { Temperature } \\
\left({ }^{\circ} \mathrm{C}\right)\end{array}$} & \multirow{2}{*}{$\begin{array}{c}\text { Extraction } \\
\text { time (h) }\end{array}$} & \multicolumn{3}{|c|}{ Total flavonoid content ( $\mu \mathrm{g} \mathrm{CE} / \mathrm{g}$ ) } \\
\hline & & QSLE $^{1)}$ & LJLE $^{2)}$ & CTLE $^{3)}$ \\
\hline \multirow{5}{*}{70} & 1 & $50.59 \pm 2.98^{(4) A 5)}$ & $36.92 \pm 2.15^{\mathrm{eBB}}$ & $8.93 \pm 0.52^{9 \mathrm{CC}}$ \\
\hline & 2 & $51.89 \pm 5.17^{\mathrm{cdA}}$ & $34.97 \pm 0.52^{\mathrm{eAB}}$ & $13.49 \pm 0.52^{\mathrm{efC}}$ \\
\hline & 3 & $57.09 \pm 1.13^{\mathrm{abA}}$ & $34.32 \pm 0.00^{\mathrm{fB}}$ & $12.19 \pm 2.98^{\mathrm{fC}}$ \\
\hline & 4 & $57.09 \pm 1.13^{\mathrm{aA}}$ & $46.68 \pm 0.52^{\mathrm{abB}}$ & $13.49 \pm 1.13^{\mathrm{efC}}$ \\
\hline & 5 & $58.40 \pm 1.13^{\mathrm{aA}}$ & $46.68 \pm 1.13^{\mathrm{abB}}$ & $16.74 \pm 1.12^{\text {cdeC }}$ \\
\hline \multirow{5}{*}{80} & 1 & $42.13 \pm 1.95^{\mathrm{eA}}$ & $42.13 \pm 0.00^{\mathrm{cdB}}$ & $12.84 \pm 3.90^{\mathrm{efC}}$ \\
\hline & 2 & $50.59 \pm 1.13^{\mathrm{dA}}$ & $42.13 \pm 1.29^{\mathrm{cdB}}$ & $12.84 \pm 0.31^{\mathrm{efC}}$ \\
\hline & 3 & $58.40 \pm 1.13^{\mathrm{aA}}$ & $47.98 \pm 0.25^{\mathrm{aB}}$ & $14.79 \pm 0.41^{\mathrm{defC}}$ \\
\hline & 4 & $58.40 \pm 1.13^{\mathrm{aA}}$ & $47.98 \pm 0.11^{\mathrm{aB}}$ & $15.44 \pm 0.24^{\text {cdeC }}$ \\
\hline & 5 & $56.44 \pm 1.13^{\mathrm{aA}}$ & $44.08 \pm 1.13^{\text {abcB }}$ & $15.44 \pm 1.13^{\mathrm{cdeC}}$ \\
\hline \multirow{5}{*}{90} & 1 & $52.54 \pm 1.13^{\text {abcA }}$ & $34.32 \pm 0.24^{\mathrm{AB}}$ & $18.05 \pm 0.12^{\mathrm{ddC}}$ \\
\hline & 2 & $54.44 \pm 1.13^{\mathrm{abcA}}$ & $38.87 \pm 2.25^{\mathrm{deB}}$ & $20.00 \pm 1.13^{\mathrm{abC}}$ \\
\hline & 3 & $56.44 \pm 1.13^{\mathrm{aA}}$ & $38.87 \pm 1.13^{\mathrm{deB}}$ & $22.60 \pm 0.66^{\mathrm{aC}}$ \\
\hline & 4 & $55.79 \pm 0.00^{\mathrm{aA}}$ & $41.48 \pm 1.95^{\mathrm{cdB}}$ & $22.60 \pm 0.54^{\mathrm{aC}}$ \\
\hline & 5 & $55.14 \pm 1.13^{\mathrm{aA}}$ & $43.10 \pm 1.29^{\mathrm{bcB}}$ & $22.60 \pm 0.76^{\mathrm{aC}}$ \\
\hline
\end{tabular}

${ }^{1)}$ QSLE, Quercus salicina Blume leaf hot water extract.

${ }^{2)}$ LULE, Ligustrum japonicum leaf hot water extract.

${ }^{3)}$ CTLE, Clerodendrum trichotomum leaf hot water extract.

${ }^{4) a-g}$ Means with the same superscripts in a column are not significantly different by Duncan's multiple range test $(\mathrm{p}<0.05)$.

${ }_{5 A-C}$ Means with the same superscripts in a row are not significantly different by Duncan's multiple range test $(\mathrm{p}<0.05)$.

\section{1-Diphenyl-2-picrylhydrazyl(DPPH) radical 소거 활성 측정}

항산화제의 경우 신체 내에서 발생하는 활성산소종을 억제하기 위해 다양한 방식으로 연구가 이루어지고 있다 (23). Table 6은 QSLE, LJLE, CTLE의 DPPH radical 소거 활성을 측정하여 나타내었다. 가장 높은 활성을 나타내고 있는 것은 $\mathrm{QSLE}$ 이며 30.21-43.02\%의 범위로 측정되었으 며, $80^{\circ} \mathrm{C}$ 3시간이 가장 높은 활성으로 측정되었고, 그 이후 에는 추출시간과 추출온도가 증가하여도 유의적인 차이가 없었다. LJLE은 $13.93-20.30 \%$ 로 측정되었고, $90^{\circ} \mathrm{C}$ 4시간에 서 가장 높은 활성을 보였다. CTLE은 5.37-11.23\%으로 가 장 낮은 활성을 보이고 있었고, $90^{\circ} \mathrm{C}$ 4시간에서 가장 높은 활성으로 측정되었다. 가장 높은 활성을 나타내고 있는 $\mathrm{QSLE}$ 의 경우 $43.02 \%$ 로 가장 낮은 활성을 보이는 CTLE과 비교해봤을 때 약 $30 \%$ 정도 차이가 나고 있었는데, 이는 항산화 활성에 영향을 미치는 페놀함량과 연관이 있을 것으 로 보였다. Dudonne 등(24)의 보고에 의하면 DPPH radical 소거 활성을 측정한 결과, 월계수 잎 추출물은 $18.93 \%$, 파파 야 잎 추출물은 $1.22 \%$, 백합나무 잎 추출물은 $3.99 \%$ 로 측정 되었고 QSLE, LJLE, CTLE와 비교하였을 때 QSLE, LJLE 는 다른 추출물에 비해 높은 DPPH radical 소거 활성으로
측정되었다. 또한 Annegowda 등(25)의 연구에 의하면 항산 화 활성은 페놀 화합물의 추출과도 연관이 있다고 하였다. 또한 모든 추출물의 항산화 활성은 활성산소종을 감소시킬 수 있는 기능적 활성이 페놀 화합물의 추출에 따라 달라질 수 있다고 하였다(26). 그러므로 세 가지 잎 열수 추출물의 항산화 활성과 총 페놀 함량의 정의 상관관계 또한 앞에 언급한 보고들과 마찬가지로 유사한 결과를 나타내었다.

Table 6. DPPH radical scavenging activity of QSLE, LJLE, and CTLE extracted under different conditions

\begin{tabular}{|c|c|c|c|c|}
\hline \multirow{2}{*}{$\begin{array}{l}\text { Temperature } \\
\left({ }^{\circ} \mathrm{C}\right)\end{array}$} & \multirow{2}{*}{$\begin{array}{l}\text { Extraction } \\
\text { time (h) }\end{array}$} & \multicolumn{3}{|c|}{ DPPH radical scavenging activity $(\%)$} \\
\hline & & QSLE $^{1)}$ & LLLE $^{2)}$ & CTLE $^{3)}$ \\
\hline \multirow{5}{*}{70} & 1 & $38.61 \pm 1.34^{\text {abc4)A5 }}$ & $13.93 \pm 0.40^{\mathrm{hB}}$ & $5.37 \pm 0.28^{\mathrm{gC}}$ \\
\hline & 2 & $37.45 \pm 4.18^{\mathrm{abcA}}$ & $15.08 \pm 0.05^{\mathrm{gB}}$ & $5.45 \pm 0.41^{\mathrm{fg} \mathrm{C}}$ \\
\hline & 3 & $39.92 \pm 3.07^{\mathrm{abcA}}$ & $14.93 \pm 0.33^{\mathrm{ghB}}$ & $5.75 \pm 0.31^{\mathrm{fgC}}$ \\
\hline & 4 & $30.65 \pm 4.88^{\mathrm{abcA}}$ & $16.79 \pm 0.00^{\mathrm{eB}}$ & $5.92 \pm 0.10^{\mathrm{eC}}$ \\
\hline & 5 & $30.21 \pm 1.73^{\mathrm{bcA}}$ & $16.65 \pm 0.13^{\mathrm{etB}}$ & $7.12 \pm 0.10^{\mathrm{efC}}$ \\
\hline \multirow{5}{*}{80} & 1 & $28.70 \pm 1.29^{\mathrm{cA}}$ & $14.41 \pm 0.18^{\mathrm{bB}}$ & $7.32 \pm 0.35^{\mathrm{dC}}$ \\
\hline & 2 & $31.73 \pm 2.86^{\mathrm{abcA}}$ & $15.72 \pm 0.05^{\mathrm{fB}}$ & $7.12 \pm 0.10^{\mathrm{dC}}$ \\
\hline & 3 & $43.39 \pm 1.96^{\mathrm{aA}}$ & $16.16 \pm 0.10^{\mathrm{efB}}$ & $7.23 \pm 0.27^{\mathrm{dB}}$ \\
\hline & 4 & $34.67 \pm 2.30^{\mathrm{abcA}}$ & $19.34 \pm 0.45^{\mathrm{bB}}$ & $8.87 \pm 0.10^{\mathrm{dC}}$ \\
\hline & 5 & $36.07 \pm 7.41^{\mathrm{abcA}}$ & $17.64 \pm 0.13^{\mathrm{dB}}$ & $8.87 \pm 0.10^{\mathrm{CC}}$ \\
\hline \multirow{5}{*}{90} & 1 & $35.84 \pm 2.00^{\mathrm{abcA}}$ & $18.66 \pm 0.35^{\mathrm{bB}}$ & $10.00 \pm 0.43^{\mathrm{CC}}$ \\
\hline & 2 & $35.58 \pm 6.68^{\mathrm{abcA}}$ & $18.69 \pm 0.10^{\mathrm{bcB}}$ & $10.00 \pm 0.43^{\mathrm{bC}}$ \\
\hline & 3 & $36.80 \pm 13.53^{\mathrm{abcA}}$ & $18.17 \pm 0.20^{\mathrm{cdB}}$ & $10.38 \pm 0.10^{\mathrm{bB}}$ \\
\hline & 4 & $38.09 \pm 1.64^{\mathrm{abcA}}$ & $20.30 \pm 0.55^{\mathrm{aB}}$ & $11.20 \pm 0.09^{\mathrm{aC}}$ \\
\hline & 5 & $43.02 \pm 2.13^{\mathrm{abA}}$ & $19.16 \pm 0.93^{\mathrm{bB}}$ & $11.23 \pm 0.05^{\mathrm{aC}}$ \\
\hline
\end{tabular}

${ }^{1)}$ QSLE, Quercus salicina Blume leaf hot water extract.

${ }^{2}$ LULE, Ligustrum japonicum leaf hot water extract.

${ }^{3}$ CTLE, Clerodendrum trichotomum leaf hot water extract.

${ }^{4) \text { ah }}$ Means with the same superscripts in a column are not significantly different by Duncan's multiple range test $(\mathrm{p}<0.05)$.

${ }_{5 \mathrm{~A}-\mathrm{C}}$ Means with the same superscipts in a row are not significantly different by Duncan's multiple range test $(\mathrm{p}<0.05)$

\section{ABTS assay에 의한 radical 소거 활성 측정}

QSLE, LJLE, CTLE의 ABTS radical 소거 활성은 각각 $26.08-28.28 \%, 17.31-25.36 \%, 12.17-21.47 \%$ 로 측정되었다 (Table 7). QSLE가 LJLE와 CTLE 보다 높은 ABTS radical 소거 활성을 가지고 있었다. QSLE의 ABTS radical 소거 활성은 $70^{\circ} \mathrm{C}$ 에서 가장 높았으며, 추출온도와 시간이 증가 할수록 감소하는 경향을 보이고 있었다. LJLE의 경우 추출 시간이 증가할수록 $\mathrm{ABTS}$ 활성이 증가하였으며 $90^{\circ} \mathrm{C}, 4$ 시 간 추출물에서 가장 높은 활성으로 측정되었으며, 그 이후 는 추출 시간이 증가하여도 유의적인 차이를 보이지 않았 다. CTLE는 QSLE와 LJLE보다 낮은 활성으로 측정되었으 나, CTLE 또한 추출시간이 증가할수록 $\mathrm{ABTS}$ 활성이 증가 하고 있었으며 $90^{\circ} \mathrm{C}, 5$ 시간 추출한 추출물이 가장 높은 활성 
을 나타내었다. Bursal과 gulcin(27)의 연구에 의하면 키위 추출물의 ABTS 소거활성은 $10,20,30 \mu \mathrm{g} / \mathrm{mL}$ 농도에서 각각 7.7, 19.4, 62.5\%로 측정되었고, QSLE, LJLE, CTLE와 비교하였을 때 $20 \mathrm{\mu g} / \mathrm{mL}$ 농도까지는 QSLE의 소거활성이 높았으나, $30 \mathrm{\mu g} / \mathrm{mL}$ 농도의 키위추출물보다는 낮은 소거활 성을 나타내고 있었다. 또한 Atoui 등(28)의 연구에 의하면 페놀 함량의 증가는 항산화 활성을 높이고, 수소 원자 및 단일 전자 이동을 통해 자유 라디칼과 활성산소종을 제거한 다고 하였다. ABTS 활성 또한 페놀 함량에 영향을 받기 때문에 QSLE가 가장 높은 활성을 나타내었지만, 추출 온도 와 시간이 증가할수록 $\mathrm{ABTS}$ radical 소거 활성이 감소하는 결과는 추후 추가적인 연구가 필요할 것으로 생각되었다.

결론적으로 QSLE, LLE, CTLE의 이화학적 특성과 항산 화 활성을 비교해보았을 때, 가장 높은 활성을 가지고 있는 것은 QSLE로 생각되었다. 추출온도와 시간별로 세 가지 추출물을 비교해 보았을 때는 QSLE의 경우 $80^{\circ} \mathrm{C} 3$ 시간에 서 가장 높은 활성을 보이고 있었으며, LLE는 $90^{\circ} \mathrm{C} 4$ 시간, CTLE는 $90^{\circ} \mathrm{C} 5$ 시간동안 추출한 것이 높은 활성으로 측정 되었다. QSLE의 경우 다른 두 가지의 추출물에 비해 높은 총 페놀, 플라보노이드 함량을 가지고 있었고, 항산화 활성 도 가장 높았다. 향후 세 가지 추출물의 식품소재로 활용

Table 7. ABTS radical scavenging activity of QSLE, LJLE, and CTLE extracted under different conditions

\begin{tabular}{ccccc}
\hline \multirow{2}{*}{$\begin{array}{c}\text { Temperature } \\
\left({ }^{\circ} \mathrm{C}\right)\end{array}$} & $\begin{array}{c}\text { Extraction } \\
\text { time }(\mathrm{h})\end{array}$ & \multicolumn{3}{c}{ ABTS radical scavening activity $(\%)$} \\
\cline { 3 - 5 } & 1 & $28.28 \pm 0.03^{\mathrm{a} 4) \mathrm{AS})}$ & $17.31 \pm 0.27^{\mathrm{B}}$ & $12.17 \pm 1.41^{\mathrm{hC}}$ \\
& 2 & $28.11 \pm 0.12^{\mathrm{aA}}$ & $18.61 \pm 0.22^{\mathrm{B}}$ & $14.31 \pm 0.38^{\mathrm{fgC}}$ \\
70 & 3 & $27.72 \pm 0.10^{\mathrm{bA}}$ & $19.36 \pm 0.32^{\mathrm{hB}}$ & $14.41 \pm 0.15^{\mathrm{fgC}}$ \\
& 4 & $27.58 \pm 0.03^{\mathrm{bcA}}$ & $20.11 \pm 0.27^{\mathrm{gB}}$ & $14.52 \pm 0.38^{\mathrm{fC}}$ \\
& 5 & $27.41 \pm 0.11^{\mathrm{bcA}}$ & $20.38 \pm 0.22^{\mathrm{gB}}$ & $14.45 \pm 0.24^{\mathrm{fgC}}$ \\
\hline & 1 & $27.43 \pm 0.13^{\mathrm{bcA}}$ & $20.72 \pm 0.27^{\mathrm{fB}}$ & $13.97 \pm 0.22^{\mathrm{gC}}$ \\
& 2 & $27.33 \pm 0.11^{\mathrm{cA}}$ & $21.00 \pm 0.16^{\mathrm{eB}}$ & $14.62 \pm 0.57^{\mathrm{fC}}$ \\
& 3 & $26.87 \pm 0.20^{\mathrm{deA}}$ & $22.73 \pm 0.45^{\mathrm{dB}}$ & $15.23 \pm 0.31^{\mathrm{eC}}$ \\
& 4 & $26.55 \pm 0.17^{\mathrm{deA}}$ & $22.97 \pm 0.28^{\mathrm{dB}}$ & $15.51 \pm 0.16^{\mathrm{eC}}$ \\
& 5 & $26.12 \pm 0.17^{\mathrm{fA}}$ & $22.56 \pm 0.22^{\mathrm{dB}}$ & $15.54 \pm 0.15^{\mathrm{eC}}$ \\
\hline & 1 & $27.18 \pm 0.20^{\mathrm{deA}}$ & $22.53 \pm 0.27^{\mathrm{dB}}$ & $17.31 \pm 0.22^{\mathrm{dC}}$ \\
& 2 & $26.58 \pm 0.17^{\mathrm{eA}}$ & $23.79 \pm 0.16^{\mathrm{CB}}$ & $18.68 \pm 0.66^{\mathrm{CC}}$ \\
& 3 & $26.92 \pm 0.43^{\mathrm{deA}}$ & $24.30 \pm 0.20^{\mathrm{bB}}$ & $20.31 \pm 0.51^{\mathrm{bC}}$ \\
& 4 & $26.44 \pm 0.11^{\mathrm{efA}}$ & $25.29 \pm 0.16^{\mathrm{aB}}$ & $20.38 \pm 0.22^{\mathrm{bC}}$ \\
& 5 & $26.08 \pm 0.17^{\mathrm{fA}}$ & $25.36 \pm 0.15^{\mathrm{aB}}$ & $21.47 \pm 0.43^{\mathrm{aC}}$ \\
\hline
\end{tabular}

${ }^{1)}$ QSLE, Quercus salicina Blume leaf hot water extract.

${ }^{2)}$ LLEE, Ligustrum japonicum leaf hot water extract.

${ }^{3)}$ CTLE, Clerodendrum trichotomum leaf hot water extract.

${ }^{4) a-j}$ Means with the same superscripts in a column are not significantly different by Duncan's multiple range test $(\mathrm{p}<0.05)$.

${ }_{5 A-C}$ Means with the same superscripts in a row are not significantly different by Duncan's multiple range test $(\mathrm{p}<0.05)$.
시 다양한 소재로서의 활용 가능성을 제시해주며, 민간요 법으로 알려진 기능성에 대한 추가적인 연구가 앞으로 더 이루어져야 할 것으로 생각된다.

\section{요 약}

추출온도와 시간을 달리한 QSLE, LJLE, CTLE 잎 열수 추출물의 이화학적 특성과 항산화 활성을 조사하여 비교하 였다. 추출온도는 $70,80,90^{\circ} \mathrm{C}$, 추출시간은 $1,2,3,4,5$ 시간 으로 추출하였으며, 그 결과 색도는 LJLE와 CTLE의 $\mathrm{L}^{*}$ 값과 $\mathrm{a}^{*}$ 값은 추출시간 및 온도가 증가함에 따라 감소하였 고, $\mathrm{b}^{*}$ 값의 경우 세 가지 추출물 모두 추출시간과 온도가 증가함에 따라 유의적으로 증가하였다. $\mathrm{pH}$ 는 $\mathrm{QSLE}$ 와 LJLE는 추출시간과 온도가 증가함에 따라 감소하였으나, CTLE의 경우 반대의 경향을 나타내었다. QSLE와 CTLE의 가용성 고형분 함량은 모든 온도에서 추출 시간이 4시간까 지 증가하였고, 그 이후로는 유의적 차이를 보이지 않았다. LJLE의 가용성 고형분 함량은 추출온도와 시간에 영향을 미치지 않았다. 총 페놀 및 플라보노이드 함량의 경우 QSLE 가 가장 높았고, CTLE가 가장 낮았다. QSLE, LJEE는 $80^{\circ} \mathrm{C}$ 에서 3시간 이후로는 추출온도와 시간이 증가하여도 유의 적 차이를 보이지 않았다. 항산화 활성인 DPPH radical 소거 활성을 측정하였을 때 QSLE가 가장 높은 활성으로 측정되 었고, CTLE가 가장 낮은 활성을 나타내었다. QSLE는 $80^{\circ} \mathrm{C}$ 3 시간 이후로 유의적 차이를 보이지 않았고, LLE, CTLE는 $90^{\circ} \mathrm{C}$ 에서 4시간에서 가장 높은 활성을 보였다. ABTS radical 소거 활성의 경우 QSLE는 추출시간과 온도가 증가 할수록 감소하는 경향을 보였으며, LJLE, CTLE는 추출시 간과 온도가 증가할수록 유의적으로 증가하였다. 결론적으 로, 추출시간과 온도를 달리한 QSLE, LLE, CTLE의 이화 학적 특성 및 항산화 활성을 측정 결과, $\mathrm{QSLE}$ 는 $80^{\circ} \mathrm{C}$ 에서 3 시간, $\mathrm{LJLE}$ 는 $90^{\circ} \mathrm{C}$ 에서 4 시간 CTLE는 $90^{\circ} \mathrm{C}$ 에서 5 시간 추출하는 조건에서 가장 높은 활성으로 측정되었다.

\section{감사의 글}

본 연구는 산림청(한국임업진흥원) 산림과학기술 연구 개발사업(2017066A00-1819-BA01)의 지원에 의하여 이루 어진 것입니다.

\section{References}

1. Cho KH, Choi JH, Jeon H (2011) Anti-inflammatory effect of Quercus salicina in IFN-y/LPS-stimulated mouse 
peritoneal macrophage. Korean J Orient Physiol Pathol, $25,540-545$

2. Kim JI, Kim HH, Kim SG, Lee KT, Ham IH, Whang WK (2008) Antioxidative compounds from Quercus salicina blume stem. Arch Pharmacal Res, 31, 274-278

3. Lee JH, Chang SY, Yook CS (1999) Studies on the morphology and chemical components of Ligustrum obtusifolium and other Ligustrum spp.. Bull K H Pharm Sci, 27, 21-30

4. Sung SY, Kim ES, Lee KY, Lee MK, Kim YC (2006) A new neuroprotective compound of Ligustrum japonicum leaves. Planta Med, 72, 62-64

5. Papoti VT, Pegklidou K, Perifantsi E, Nenadis N, Demopoulos V, Tsimidou MZ (2011) Antioxidant and aldose reductase inhibition activity of Ligustrum japonicum and Olea europaea L. leaf extracts. Eur J Lipid Sci Technol, 113, 876-885

6. Kim JH, Song HN, Ko HC, Lee JY, Jang MG, Kim $\mathrm{Sj}$ (2017) Anti-oxidant and anti-inflammatory properties of Clerodendrum trichotomum leaf extracts. J Life Sci, 27, 640-645

7. Kim KH, Kim SG, Jung MY, Ham IH, Whang WK (2009) Anti-inflammatory phenylpropanoid glycosides from Clerodendron trichotomum leaves. Arch Pharmacal Res, $32,7-13$

8. AOAC (1990) Official Method of Analysis of AOAC Intl. $15^{\text {th }}$ ed, Method 950.46, Association of Official Analytical Chemists, Arlington, VA, USA

9. Kwon JH, Belanger JMR, Pare JRJ (2003) Optimization of microwave assisted extraction (MAP) for ginseng components by response surface methodology. J Agric Food Chem, 51, 1807-1810

10. Lee BR, Muneer S, Jung WJ, Avice JC, Ourry A, Kim TH (2012) Mycorrhizal colonization alleviates droughtinduced oxidative damage and lignification in the leaves of drought-stressed perennial ryegrass (Lolium perenne). Physiol Plant, 145, 440-449

11. Das PR, Eun JB (2018) A comparative study of ultra-sonication and agitation extraction techniques on bioactive metabolites of green tea extract. Food Chem, 253, 22-29

12. Lee LS, Kim SH, Kim YB, Kim YC (2014) Quantitative analysis of major constituents in green tea with different plucking periods and their antioxidant activity. Molecules, 19, 9173-9186

13. Thaipong K, Boonprakob U, Crosby K, CisnerosZevallos L, Byrne DH (2006) Comparison of ABTS,
DPPH, FRAP, and ORAC assays for estimating antioxidant activity from guava fruit extracts. J Food Compos Anal, 19, $669-675$

14. Zielinski AAF, Haminiuk CWI, Alberti A, Nogueira A, Demiate IM, Granato D (2014) A comparative study of the phenolic compounds and the in vitro antioxidant activity of different Brazilian teas using multivariate statistical techniques. Food Res Int, 60, 246-254

15. Seo YC, Kim IS, Chung DO, Eun JB (2014) Physicochemical properties and sensory evaluation of a green tea infusion extracted from green tea for cold water extraction at low temperature for different times. Korean Tea Soc, 20, 91-97

16. Choi HJ, Lee WS, Hwang SJ, Lee IJ, Shin DH, Kim HY, Kim KU (2000) Changes in chemical compositions of green tea (Camellia sinensis L.) under the different extraction conditions. Korean J Life Sci, 10, 202-209

17. Jang MJ, Ha HJ, Yoon SR, Noh JE, Kwon JH (2006) Prediction of optimal leaching conditions for green tea. J Korean Soc Food Sci Nutr, 35, 747-753

18. Gulcin I, Sat IG, Beydemir S, Elmastas M, Kufrevioglu OI (2004) Comparison of antioxidant activity of clove (Eugenia caryophylata Thunb) buds and lavender (Lavandula stoechas L.). Food Chem, 87, 393-400

19. Gulcin I (2005) The antioxidant and radical scavenging activities of black pepper (Piper nigrum) seeds. Int $\mathbf{J}$ Food Sci Nutr, 56, 491-499

20. Serbetci TH, Gulcin I (2010) Antioxidant and radical scavenging activity of aerial parts and roots of Turkish liquorice (Glycyrrhiza glabra L.). Int J Food Prop, 13, 657-671

21. Kim HY, Koo SC, Kang BK, Lee YH, Kim HT, Yun HT, Baek IY, Jeong HS, Choi MS (2014) Growth characteristics of sprouts and changes of antioxidant activities in common bean (Phaseolus vulgaris L.) with cultivated temperature. Korean J Crop Sci, 59, 201-207

22. Zhou J, Zheng X, Yang Q, Liang Z, Li D, Yang X, $\mathrm{Xu} \mathrm{J}$ (2013) Optimization of ultrasonic-assisted extraction and radical-scavenging capacity of phenols and flavonoids from Clerodendrum cytophyllum Turcz leaves. PLOS, 8, e68392

23. Masaki H, Sakaki S, Atsumi T, Sakurai H (1995) Active oxygen scavenging activity of plants extracts. Biol Pharm Bull, 18, 162-166

24. Dudonne S, Vitrac X, Coutiere P, Woillez M, Merillon JM (2009) Comparative study of antioxidant properties and total phenolic content of 30 plant extracts of industrial 
interest using DPPH, ABTS, FRAP, SOD, and ORAC assays. J Agric Food Chem, 57, 1768-1774

25. Annegowda HV, Bhat R, Min-Tze L, Karim AA, Mansor SM (2012) Influence of sonication treatments and extraction solvents on the phenolics and antioxidants in star fruits. J Food Sci Technol, 49, 510-514

26. Dangles O (2006) The physico-chemical properties of polyphenols: How do they relate to their roles in plants, foods, and human health. Agro Food Ind Hi-Tech, 17, 64-67
27. Bursal E, Gulcin I (2011) Polyphenol contents and in vitro antioxidant activities of lyophilised aqueous extract of kiwifruit (Actinidia deliciosa). Food Res Int, 44, 1482-1489

28. Atoui AK, Mansouri A, Boskou G, Kefalas P (2005) Tea and herbal infusions: Their antioxidant activity and phenolic profile. Food Chem, 89, 27-36 